\title{
STRESS ANALYSIS AND FATIGUE LIFE PREDICTION OF WING- FUSELAGE LUG JOINT ATTACHMENT BRACKET OF A TRANSPORT AIRCRAFT
}

\author{
Sriranga B.k ${ }^{1}$, Kumar . ${ }^{2}$ \\ ${ }^{I}$ M.Tech Scholar, Dept. Of Mech. Engg., M.S. Ramaiah Institute of Technology, Bangalore \\ ${ }^{2}$ Assistant Professor, Dept. Of Mech. Engg M.S. Ramaiah Institute of Technology, Bangalore
}

\begin{abstract}
Civil transport aircraft is used for ferrying passengers from one place to another. Aircraft is a highly complex flying structure. Generally transport aircraft undergoes nominal maneuring flights. During the flight when the maximum lift is generated, the wings of the aircraft will undergo highest bending moment. The bending moment will be maximum at the root of the wing which caused highest stress at this location. Wings are attached to the fuselage structure through wing-fuselage attachment brackets. The bending moment and shear loads from the wing are transferred to the fuselage through the attachment joints. In this project bending load transfer joint is considered for the analysis. First one needs to ensure the static load carrying capability of the wing-fuselage attachment bracket. Stress analysis will be carried out for the given geometry of the wing-fuselage attachment bracket. Finite element method is used for the stress analysis. In the current project, an attempt will be made to predict the fatigue life of wing-fuselage attachment bracket in a transport airframe. In a metallic structure fatigue manifests itself in the form of a crack which propagates. Fatigue cracks will appear at the location of high tensile stress locations. These locations are invariably of high stress concentration. Fatigue life calculation will be carried out for typical service loading condition using constant amplitude $S$-N data for various stress ratios and local stress history at stress concentration. In this paper for modeling CATIA V5 software is used and for analysis tool MSC/ PATRAN and MSC/ NASTRAN 2010.
\end{abstract}

Keywords: Transport aircraft, Lift load, Bending moment, Wing-fuselage attachment, stress concentration, Fatigue-life, $S$ - $N$ data, Stress ratio.

\section{INTRODUCTION}

\subsection{Introduction to Lug Attachment Joints}

Lugs are the primary structural elements in airframe structure that are widely used in connecting different components of the airframe. For ex. aircraft engine-pylon support fittings, wing fuselage attachment, and landing gear links are some of the typical applications where attachment lugs of various configurations can be found. [1]

The catastrophic failure is occurring may lead to lug joint bracket of the aircraft structure. Therefore, Finite element analysis (static) and experimental (numerical) data helps the designer to life of the structure from catastrophic failure. Aircraft lug joint bracket is most fracture critical components in aircraft wing-fuselage structure, and the consequences of structural lug failure can be very severe (disastrous) (it is so severe (disastrous) that quite a few times the fuselage and wings of an aircraft gets separated). Therefore, it is important to establish design criteria and analysis methods to ensure the damage tolerance of aircraft attachment lugs. [4]
Advantages of lugs are as follows:

1) A lug has a simple geometry with a well defined load transmission compared to bolted and riveted joints. In the latter types of joints, load transmission occurs partly by frictional forces between the plates which are clamped by the fasteners.

2) Lugs occur at various locations in an aircraft structure, either for easy assembling of major components, or for the possibility of rotation (e.g. landing gears, control rods, for joining wing and fuselage). In such cases crack in a lug can lead Fail-Safe problems, and information of crack growth behavior is important.

\section{GEOMETRICAL CONFIGURATION}

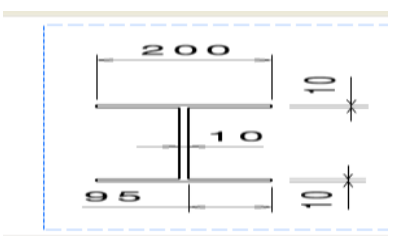

Fig a 


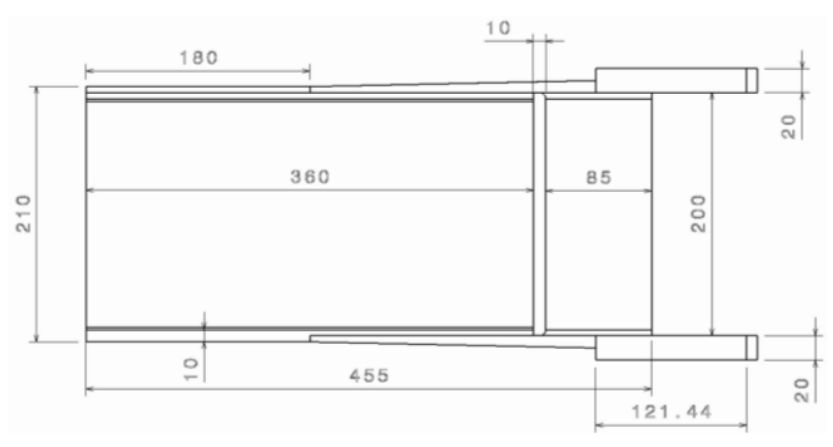

Fig $b$

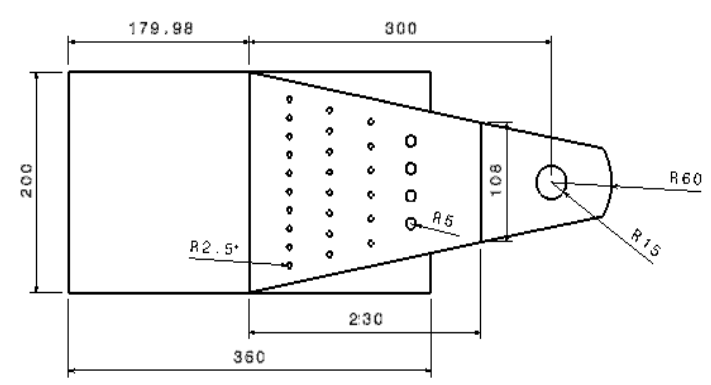

Fig c

Fig.2.1 a, b, c, shows three views of wing fuselage lug Joint bracket.

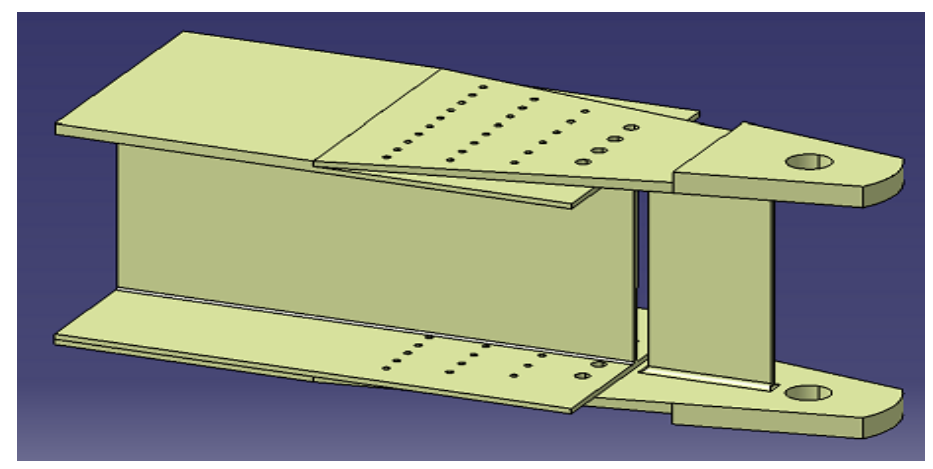

Fig.2.2: Isometric view of the lug joint bracket

The geometric dimensions of the lug attachment bracket are shown in the figure below. Three views of wing fuselage lug attachment bracket are shown in the Figure 2.1. A three dimensional view of the lug attachment bracket is shown in the figure 2.2.

\section{MATERIAL SPECIFICATION}

- Density (weight)

- Stiffness (young's modulus)

- Strength (ultimate and yield strengths)
Durability (fatigue)

- Damage tolerance (fracture toughness and crack growth)

- Corrosion

Seldom is a single material able to deliver all desired properties in all components of the aircraft structure. A combination of various materials is often necessary.

\subsection{Alloy Steel, Heat Treated AISI-4340}

The material considered for the lug joint bracket of the structure is steel alloy AISI4340.

The following properties

1. Young's Modulus, $\mathrm{E}=2.1 \mathrm{E} 5 \mathrm{~N} / \mathrm{mm}^{2}$

2. Density $=7800 \mathrm{~kg} / \mathrm{mm}^{3}$

3. Poison's Ratio, $\mu=0.3$

4. Yield Strength, $\sigma_{\mathrm{y}}=1014.3 \mathrm{~N} / \mathrm{mm}^{2}$.

5. Ultimate Strength, $\sigma_{\mathrm{u}}=1035 \mathrm{~N} / \mathrm{mm}^{2}$

\subsection{Aluminum Alloy - 2024-T351}

The material considered for the I section wing spar and rivets joint of the wing structure is aluminum alloy-2024T351.

1. Density $=2800 \mathrm{~kg} / \mathrm{mm}^{3}$

2. Young's Modulus, $\mathrm{E}=70000 \mathrm{~N} / \mathrm{mm}^{2}$

3. Poison's Ratio, $\mu=0.3$

4. Yield Strength, $\sigma_{\mathrm{y}}=378 \mathrm{~N} / \mathrm{mm}^{2}$.

5. Ultimate Strength, $\sigma_{\mathrm{u}}=485 \mathrm{~N} / \mathrm{mm}^{2}$

\section{LOADS ON THE WING FUSELAGE LUG}

\section{ATTACHMENT BRACKET}

The aircraft wing is carried out bending moment by the spars in the wing structure. The maximum bending moment occurs at the root of the spar where wing and fuselage components will be attached to each other. The load calculation for the wing fuselage lug attachment bracket is described in the next section.

\subsection{Load calculation for the wing fuselage lug joint} Bracket.

1) Aircraft category=medium size of fighter aircraft

2) Total weight of the aircraft $=6500 \mathrm{~kg}=63765 \mathrm{~N}$

3) Load factor considered in design $=3 \mathrm{~g}$.

4) Design limit load on the structure $=3 * 63765=1.9129 * E 5 \mathrm{~N}$

5) Design ultimate load $=1.9129 * E 5 * 1.5=2.8694 * E 5 N$

7) Distribution of lift load on fuselage and wing $=20 \%$ and $80 \%$.

8) Total Load acting on the Wings $=2.8694 * \mathrm{E} 5 \mathrm{~N} * 0.8=229.554 * \mathrm{E} 3 \mathrm{~N}$

9) Load acting on the each Wing=

$(229.554 * \mathrm{E} 3) / 2=114.777 * \mathrm{E} 3 \mathrm{~N}$

10) Number of spar in the wing $=3$ 
11) Load sharing by spars is a) spar $1=15 \%$

b) Spar $2=40 \%$

c) Spar $3=45 \%$

12) The wing fuselage attachment considered for the current analysis is at spar. Therefore, load acting on the spare $3=114.777 * \mathrm{E} 3 * 0.15=17.216 * \mathrm{E} 3 \mathrm{~N}$.

Total bending momentum acting at the root of the beam = $17.216 * \mathrm{E} 3 \mathrm{~N} * 750 \mathrm{~mm}=12.912 * \mathrm{E} 6 \mathrm{~N} / \mathrm{mm} 2$

To simulate the equivalent bending moment by applying the load at a distance of $480 \mathrm{~mm}$ which is free end of the beam considered in the analysis is $=(12.912 * \mathrm{E} 6$ $\mathrm{N} / \mathrm{mm} 2)) / 480=26.9 * \mathrm{E} 3 \mathrm{~N}$.

\section{FINITE ELEMENT MODEL OF THE WING}

\section{FUSELAGE LUG JOINT HOLE (ROOT)}

\section{BRACKET}

A finite element model is the complete idealization of the entire structural problem including the node location, the element, physical and material properties, loads and boundary conditions.

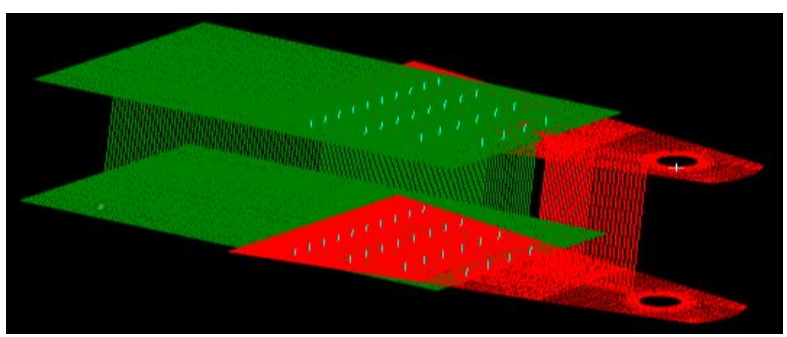

Fig.5.1 Finite element model of the wing fuselage Lug joint bracket

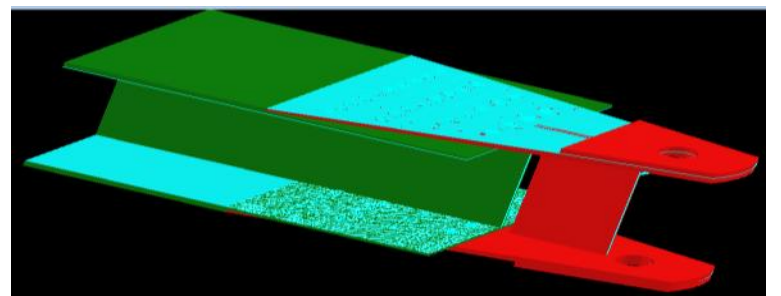

Fig.5.2 The 2-D mesh display in 3-D form to visualize the thickness of the wing fuselage lug joint model.

\subsection{The different structural members of the wing}

\section{fuselage Lug joint bracket are}

- $\quad$ Lug joint (Root section).

- I-spar (Top and bottom flanges section).

- Top and bottom flanges of the lug joint bracket.

- Riveted holes.
The corresponding mesh generated for each of the above mentioned members are shown in the figure below.

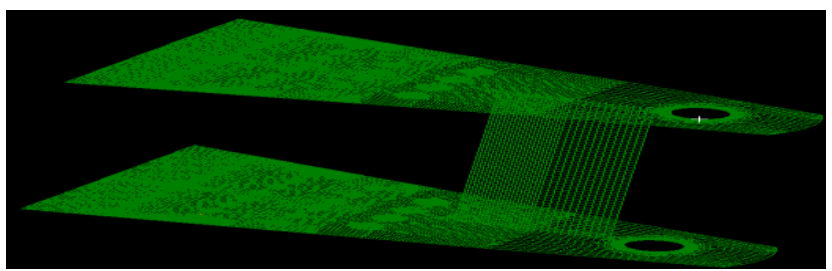

Fig.5.3 Finite Element Model of the Lug hole (Root section).

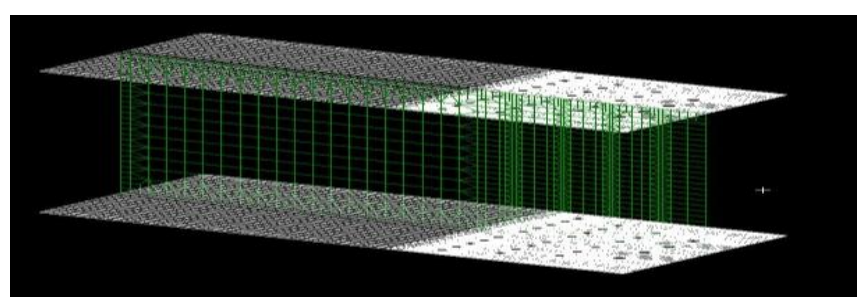

Fig.5.4 Finite Element Model of the I section Spar in wing fuselage.

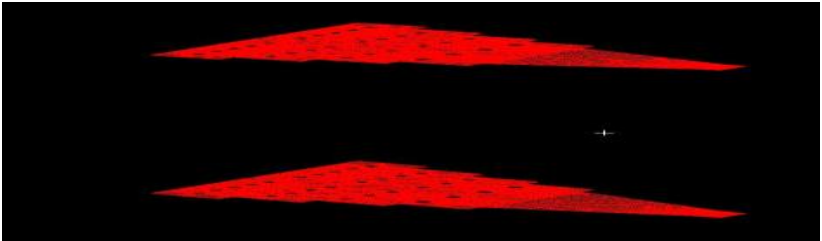

Fig.5.5 Finite Element Model of the different Thickness of the Lug Plate.

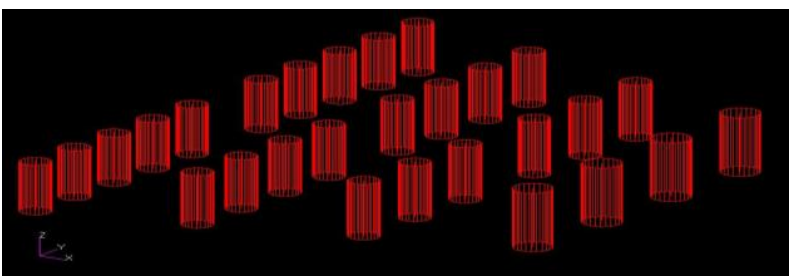

Fig.5.6 FEA Model of the Rivets jointed in the I-spar \& lug plate

\section{THE LOADS AND BOUNDARY CONDITIONS OF THE LUG JOINT IN WING FUSELAGE STRUCTURE.}

The loads and boundary conditions along with the finite element model are shown in the figure 6.1. A load 26.9E3 N of is applied at one end of the I section spar beam. This load will essentially create the required bending moment at the root section. 


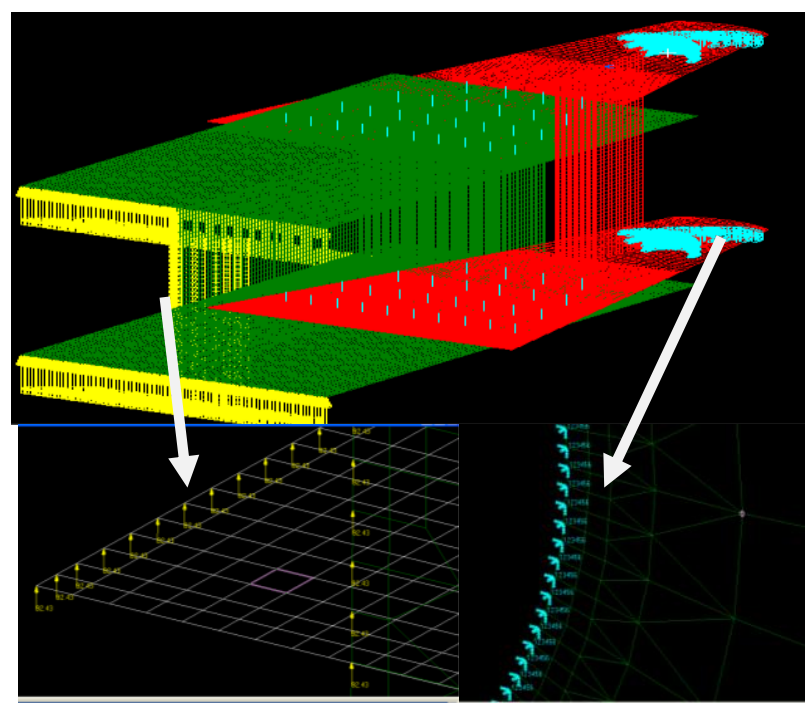

Fig.6.1 Load and Boundary conditions applied to the wing Fuselage Lug joint bracket.

\section{THE FINITE ELEMENTS OF THE} MODELLING AND STATIC STRESS ANALYSIS IN WING FUSELAGE LUG JOINT BRACKET.

The stress values at the root section of the lug hole and the displacement contours occurring are shown in the figures 7.1. A maximum stress of $919 \mathrm{~N} / \mathrm{mm} 2$ is observed at the midpoint of the root section. The maximum stress value obtained from the analysis is used as the input for the fatigue life prediction calculations.

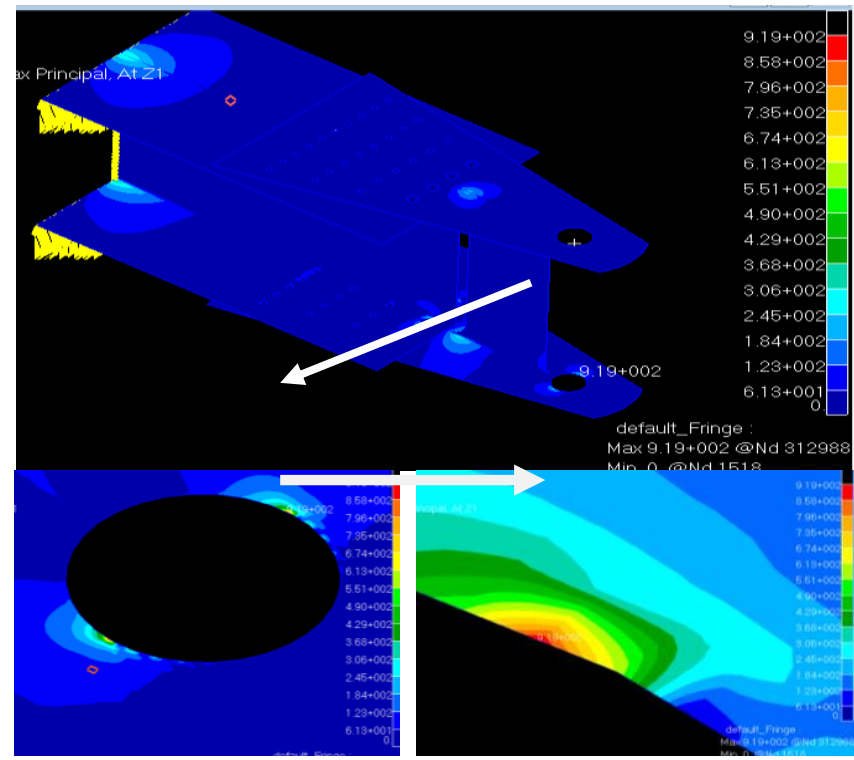

Fig 7.1 Figure Showing Maximum Stresses of Wing Fuselage Lug joint Bracket.
Table: 7.1 The Convergence criteria of the lug joint bracket

\begin{tabular}{|c|c|}
\hline NO. Of iterations & $\sigma_{\max }(\mathrm{N} / \mathrm{mm} 2)$ \\
\hline 0 & 0 \\
\hline 1 & 390.7 \\
\hline 2 & 546.4 \\
\hline 3 & 918.51 \\
\hline 4 & 919 \\
\hline 5 & 919 \\
\hline
\end{tabular}

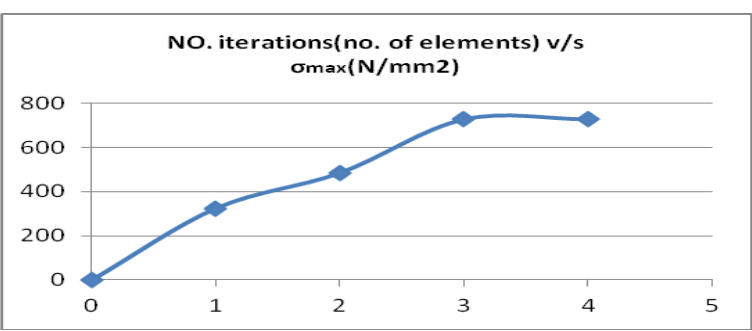

Fig.7.2 Max Stress(N/mm2) V/S No. Elements

Table 7.2: Several Iteration of Using Max Stress and Min Stress with loads

\begin{tabular}{|c|c|}
\hline $\operatorname{load}(\mathbf{N})$ & $\boldsymbol{\sigma}(\mathbf{N} / \mathbf{m m} \mathbf{2})$ \\
\hline 26900.86 & 919 \\
\hline 46900.86 & 1602.22 \\
\hline 66900.86 & 2285.45 \\
\hline 86900.86 & 2968.68 \\
\hline 106900.9 & 3651.92 \\
\hline
\end{tabular}

\section{RESULTS AND DISCUSSIONS}

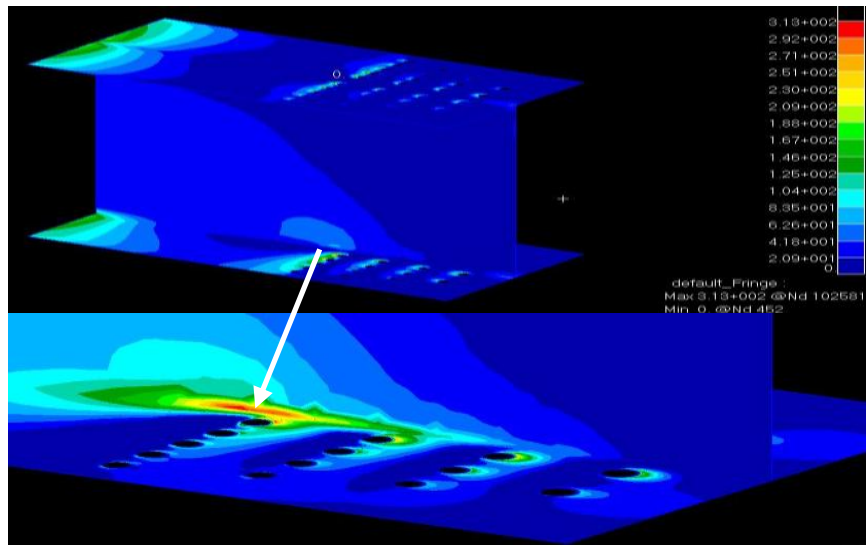

Fig 8.1 Max Stress in I-Sectional Spar Z1=3.13*E2N/mm2 


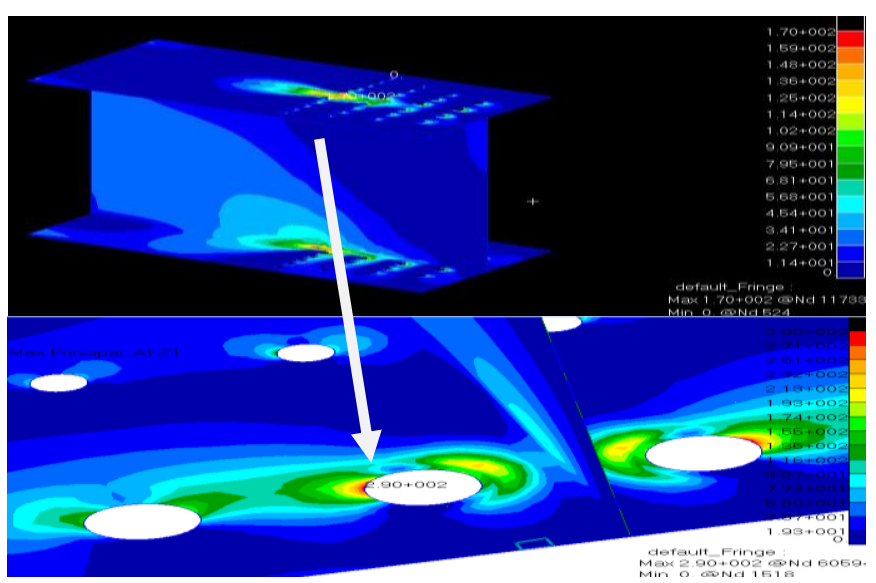

Fig.8.2 Max Stress I-Sectional Spar Z2=2.9* E2N/mm²

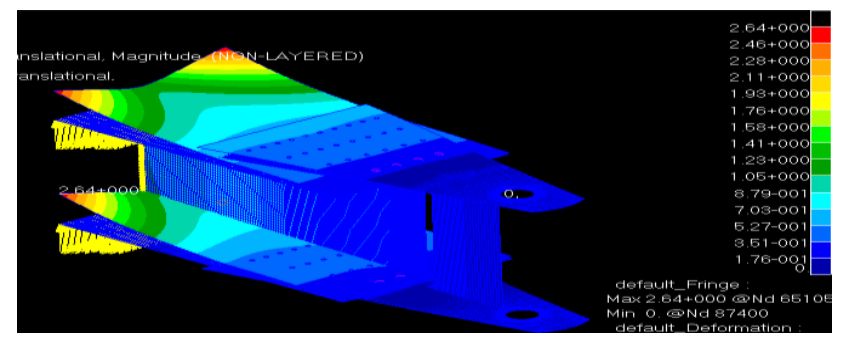

Fig.8.3 Displacement Contour of wing fuselage Lug joint Bracket. (2.64mm)

\section{CONCLUSIONS}

$>$ Damage tolerance design philosophy is generally used in the aircraft structural design to reduce the weight of the structure.

$>$ Stress analysis of the wing fuselage lug attachment bracket is carried out and maximum tensile stress is identified at one of the lug-holes.

$>$ FEM approach is followed for the stress analysis of the wing fuselage lug attachment bracket.

$>$ Maximum tensile stress of $919 \mathrm{~N} / \mathrm{mm}^{2}$ is observed in the lug.

$>$ Several iterations are carried out to obtain a mesh independent value for the maximum stress.

$>$ A fatigue crack normally initiates from the location maximum tensile stress in the structure.

\section{SCOPE FOR FUTURE WORK}

$>$ Fatigue crack growth analysis can be carried out on the wing fuselage lug attachment bracket in the bottom skin of the wing.

> Damage tolerance evaluation for the lug can be carried out for given load spectrum.

$>$ A structural testing of the wing fuselage lug attachment bracket can be carried out for the complete validation of all theoretical calculations.
$>$ Introduce an anti-corrosion layer for lugs and pin surface.

$>$ Introduce an intermediate sleeve to reduce the local stress concentration in the wing lug

\section{REFERENCES}

[1]. Stress and fatigue analysis of modified wing-fuselage connector for Agricultural aircrafts, Lujan witek, P 773-778, Volume: 43, Issue 3, Journal of Aircraft (2006).

[2]. Failure analysis of wing-fuselage connector of an agricultural aircrafts, Lujan witek, P 572-581, Volume 13, Issue 4, Engineering Failure Analysis (2006).

[3]. Damage tolerance assessment of aircraft attachment lugs . T.R. Brussat, K. Kathiresan and J.L. Rudd, LockheedCalifornia Company, Burbank, CA 91520, U.S.A., AT\&T Bell Laboratories, Marietta GA 30071, U.S.A., AFWAL/FIBEC, Wright-Patterson Air Force Base, OH 45433, U.S.A.

[4]. Stress intensity factors for cracks at attachment lugs. R. Rigby and M. H. Aliabadi, British Aerospace, Filton, Bristol BS99 7AR, U.K., Wessex Institute of Technology, Ashurst Lodge, Ashurst, Southampton S040 7AA, U.K.

[5]. Failure in lug joints and plates with holes . J. Vogwell and J. M. Minguez School of Mechanical Engineering, University of Bath, Bath BA2 7AY, U.K., Facultad de Ciencias, Universidad Del Pais Vasco, Bilbao, Spain.

[6]. Jaap Schijve, "Fatigue damage in aircraft structures, not wanted, but tolerated?" International journal of fatigue, Volume 31, Issue 6, June 2009, Pages 998-1011 